\title{
Correspondence
}

\section{Pharmacoeconomics: Sensitization of undergraduate medical students}

Pharmacoeconomics plays a vital role in the treatment of a disease. Patients are affected by the high prices of medicines. As the symptoms improve, error of compliance sets in, particularly so, if the regimen is heavy on the pocket of the patient.

One of the major causes of the high cost of medicines is prescription by brand names. For some medicines, the difference in cost between the branded and generic product varies from less than twofold to more than 100-fold. ${ }^{[1]}$ The overall savings owing to prescribing the least expensive generic preparation has been reported to be approximately $5 \%$. Savings in individual situations can be very much higher. Generic names are also less confusing. ${ }^{[2]}$

In the "therapeutic jungle", the prescriber can help the society by using generic names while prescribing. ${ }^{[2]}$ However, prescribers often do not follow this and even prescribe branded medicines over-enthusiastically. Health professionals have an important role to play in promoting quality use of medicines through good treatment choices and good communication with the patients by explaining to them about the low cost generic medicines. ${ }^{|3|}$ The doctors, therefore, must be trained during the formative years of their learning, so that they are not allured by the marketing gimmicks of pharmaceutical companies and develop a habit of prescribing by generic names. We tried this by sensitizing the students of second year professional MBBS course.

The present students were first given the concept of generic and branded medicines. They were asked to collect the prices of the same medicine in branded and generic form for some common ailments such as rhinitis, insomnia, anxiety, diabetes, low backache, fever, diarrhea, acid peptic disease and upper respiratory tract infection with the help of institu- tional pharmacist. Percentage difference in the cost of the two was calculated and the drug compliance in view of the difference in cost was discussed with the medical students.

It was noticed that all branded medicines were higher priced as compared to their generic alternatives (Table 1). Approximately a 3 to 4 times increase was observed. It was found that many times chemists did not give the specific generic medicine, which was asked for and tried to give a substitute branded medicine, giving the reason of non-availability. Sometimes, the locally manufactured alternative was given. Obviously, such indulgence resulted in some economic gains for the seller.

Generic drugs offer major savings in healthcare expenditure because they are substantially lower in price than the branded drugs. It is desired that doctors should prescribe the drugs only in the generic form except for conditions where drugs with narrow therapeutic margin are prescribed, for instance, antiepileptics, lithium carbonate, antiarrhythmics. ${ }^{[4]}$

C.S. Gautam, S. Bhanwra

Department of Pharmacology, Government Medical College \& Hospital, Chandigarh.

E-mail: doc_sangeeta@yahoo.com

\section{References}

1. Lofholm PW, Katzung BG. Rational prescribing and prescription writing. In: Katzung BG, editor. Basic and clinical phannacology. $9^{\text {th }}$ ed. New York: Mc Graw Hill; 2004. p. 1091-100.

2. Nies AS. Principles of therapeutics. In: Hardman JG, Limbird LE, editors. Goodman \& Gilman's. The phamacological basis of therapeutics. $10^{\text {th }}$ ed. New York: Mc. Graw Hill; 2001. p. 45-66.

3. Hassali A, Stewart K. Quality use of generic medicines. Aust Prescr 2004;27:801.

4. Birkett DJ. Generics - equal or not? Aust Prescr 2003;6:85-7.

Table 1

Comparative pricing of generic and branded medicines

\begin{tabular}{|c|c|c|c|c|c|c|}
\hline Generic name & No. of tab & Generic medicine & Price (Rs.) & Branded medicine & Price (Rs.) & $\%$ differece in cost \\
\hline Norfloxacin 400 mg & 10 & Norfloxacin (Okasa) & 27.00 & Norflox (Cipla) & 47.00 & 43 \\
\hline Ciprofloxacin 500 mg & 10 & Neocip (Okasa) & 50.00 & Ciplox (Cipla) & 90.00 & 44 \\
\hline Ofloxacin $200 \mathrm{mg}$ & 10 & Oflacin (Okasa) & 45.00 & Oflox (Protec) & 65.00 & 30 \\
\hline Sparfloxacin & 6 & Sparcip (Cipla) & 50.00 & Sparta (Alembic) & 60.00 & 17 \\
\hline Amoxycillin 250 mg & 10 & Amoxycillin (Cadila) & 35.00 & Novamox (Cipla) & 64.00 & 45 \\
\hline Paracetamol $500 \mathrm{mg}$ & 10 & Paracip (Cipla) & 5.50 & Ultragen (Wyeth) & 15.75 & 65 \\
\hline Diclofenac sodium 50 mg & 10 & Vova (Alembic) & 8.00 & Voveran (Novartis) & 16.60 & 52 \\
\hline Omeprazole 20 mg & 15 & Omisac(Ranbaxy) & 47.00 & Ocid (Cadila) & 64.50 & 27 \\
\hline Alprazolam 0.25 mg & 10 & Anaxil (Ranbaxy) & 5.00 & Anxit (Micro) & 10.50 & 52 \\
\hline Cetirizine $10 \mathrm{mg}$ & 10 & Cetacip (Cipla) & 10.00 & Alerid (Cipla) & 30.00 & 66 \\
\hline Chloroquine & 10 & Maligo (Cipla) & 4.50 & Lariago (IPCA) & 05.90 & 24 \\
\hline B. Complex & 10 & Bicomax forte (Nicholas) & 7.90 & Becosule (Pfizer) & 10.50 & 25 \\
\hline Metformin $500 \mathrm{mg}$ & 10 & Okamet (Okasa) & 7.15 & Gluformin (Nicholas) & 11.00 & 35 \\
\hline
\end{tabular}

